Article

\title{
Are Area-Level Crimes Associated with Older Adults' Physical Activity and Sedentary Behavior?
}

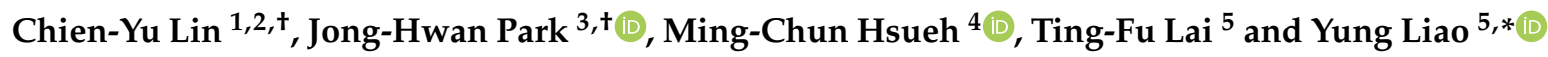 \\ 1 Graduate School of Sport Sciences, Waseda University, 2-579-15 Mikajima, Tokorozawa, \\ Saitama 359-1192, Japan; chienyulin@ntu.edu.tw or chienyulin@akane.waseda.jp \\ 2 Institute of Health Behaviors and Community Sciences, National Taiwan University, No.17, Xu-Zhou Road, \\ Zhongzheng Dist., Taipei 10055, Taiwan \\ 3 Health Convergence Medicine Research Group, Biomedical Research Institute, Pusan National University \\ Hospital, 179, Gudeok-Ro, Seo-Gu, Busan 49241, Korea; jpark@pnuh.co.kr \\ 4 Department of Physical Education, National Taiwan Normal University, 162, Heping East Road Section 1, \\ Taipei 106, Taiwan; boxeo@ntnu.edu.tw \\ 5 Department of Health Promotion and Health Education, National Taiwan Normal University, 162, \\ Heping East Road Section 1, Taipei 106, Taiwan; ted971345@gmail.com \\ * Correspondence: liaoyung@ntnu.edu.tw \\ + These authors contributed equally to this work.
}

Received: 15 March 2019; Accepted: 23 April 2019; Published: 26 April 2019

check for updates

\begin{abstract}
There is limited evidence for the associations of area-level crime with older adults' physical activity and sedentary behavior, especially in Asia. This study explored the association of area-level crime with older adults' active and sedentary behavior. A telephone-based survey of Taiwanese seniors was conducted in September-November of 2017. Data related to sociodemographic factors, residential neighborhood (objectively recorded area-level crime incidence), and time spent in physical activity and sedentary behavior, were obtained from 1068 older adults. Adjusted binary logistic regression was analyzed. Fully adjusted analyses showed older adults living in neighborhoods with a higher incidence of drug crime (odds ratio, $\mathrm{OR}=0.71,95 \%$ confidence interval, $\mathrm{CI}=0.52-0.96$ ), car theft $(\mathrm{OR}=0.70,95 \% \mathrm{CI} 0.51-0.95)$, and locomotive theft (OR $=0.69,95 \% \mathrm{CI} 0.51-0.94)$ were found to be less likely to achieve the recommendation on physical activity. In addition, those living in neighborhoods with a higher incidence of theft $(\mathrm{OR}=1.93,95 \% \mathrm{CI} 1.05-3.55)$, drug crime (OR $=1.93$, $95 \%$ CI 1.05-3.55), breaking and entering (OR $=2.04,95 \% \mathrm{CI} 1.11-3.76)$, and rape (OR $=2.20,95 \% \mathrm{CI}$ 1.20-4.06) were more likely to have more sedentary time. There were sex differences in the association of area-level crime incidence with physical activity and sedentary behavior. These findings suggest that crime prevention should be considered when designing physical activity and sedentary behavior interventions for older adults.
\end{abstract}

Keywords: crime safety; physical activity recommendations; sedentary behavior; older adults

\section{Introduction}

Physical inactivity and prolonged sedentary time are two independent risk factors for older adults' health [1]. Despite this, most older adults across countries [2] and specifically in Taiwan [3,4] still do not achieve the minimum amounts of physical activity recommendation and spend prolonged periods of time in sedentary behavior. For promoting physically active and non-sedentary lifestyles in the older adult population, it is critical to identify the relevant factors related to their active and sedentary behavior.

According to the Ecological Model of Health Behavior, multiple levels of environmental attributes play important roles in older adults' active and sedentary behavior [5,6]. However, among older adults, 
most previous studies have focused on examining the built environment $[7,8]$, with few research studies with investigated specific correlates of social-cultural environment (e.g., crime safety), as related to active and sedentary behavior [9-11]. Furthermore, only a few studies investigated the association with older adults' active and sedentary behavior using objectively measured safety from crime. One previous work from Norway showed that older men living in a higher level of neighborhood violence incidence was associated with decreased physical activity [12]. Previous studies used the audit tool, such as observing the proportion of homes with high border markers [13] and crime watch signage [14], and found that physical activity was positively associated with safety from crime. In contrast, another study observed the prevalence of signs of crime and showed a negative association with sitting behavior [15]. These previous findings used inconsistent methods and had mixed results.

Existing studies on this issue among older adults are restricted in a few ways. First, studies used some proximity indicators as the area-level safety from crime [13-15] but rarely used crime data to assess the association of crime safety with physical activity and sedentary behavior. One study used crime data, but only extracted violent crime and lacked of other types of crime [12]. Secondly, a limited number of studies have examined gender-specific associations in objectively measured crime safety and older adults' active and sedentary behaviors, with gender differences in environmental attributes related to physical activity having been widely reported [16,17]. Environmental factors seemed to have more influence on physical activity in men than in women. Most previous studies have been conducted in Western populations [12-14], with only one study from Hong Kong [15]; therefore, such data from Asian countries are still required. To address these research gaps, the present study aimed to investigate the relationship between different types of area-level crimes, and older adults' physical activity and sedentary behavior under Asian contexts. In addition, we also examine the gender difference for the development of a multi-level intervention to promote active living and avoidance of sedentary lifestyles.

\section{Materials and Methods}

\subsection{Participants}

Data for older adults aged 65 years and above were collected by conducting a computer-assisted telephone interview in 2017. We randomly dialed four-digit suffixes based on the national frame of telephone numbers. Participants aged 65 and above in Taiwan were recruited using a telephone-based survey based on an orderly two-stage random-digit dialing procedure. The population aged 65 and above were randomly sampled by their residential regions in the beginning sampling stage, and then stratified by sex and age group in the second stage. Each survey was conducted by a trained interviewer with a structured questionnaire through household telephone. A total of 3282 older adults were contacted to attend the survey and 1068 of them completed it (response rate: 32.5\%). Before the telephone interview, each participant provided verbal informed consent and was informed that they would not be offered any rewards. The study was administered as claimed by the Declaration of Helsinki, and the protocol was confirmed and agreed by the Research Ethics Committee of University (REC number: 201706HM020).

\subsection{Area-Level Crime Incidence}

Area-level crime incident counts were retrieved from open data from the National Police Agency, Ministry of the Interior, Taiwan [18]. Year-specific crime counts (2017) were assigned to the year in which participants completed the telephone-based interview. A "district" was the smallest geographical areas for counts of area-level crime incidence; therefore, two researchers manually integrated the area-level crime incident counts with each respondent's residential district. Since different types of crime could have different impacts on the engagement of physical activity and sedentary behavior [19], eight types of crime count were considered: (1) total crimes; (2) drug crimes; (3) theft; (4) burglary; 
(5) breaking and entering; (6) motor vehicle theft; (7) locomotive theft; and (8) rape. Each crime count was dichotomized into low and high levels of local crime according to the median.

\subsection{Physical Activity}

The data for physical activity were measured by the International Physical Activity QuestionnaireShort Form (IPAQ-SF) in the Taiwanese version. The IPAQ-SF had an acceptable validity (Intraclass Correlation Coefficient $[$ ICC $]=0.79$ ) among adults $[20]$ and a better validity $($ ICC $=0.81-0.89$ ) among older adults [21]. The participants were asked to report their average time spent in vigorous-intensity physical activity, moderate-intensity physical activity, and walking for the last seven days. The total physical activity was calculated and categorized into two groups (physically insufficient: less than 150 $\mathrm{min} /$ week, versus physically sufficient: $150+\mathrm{min} /$ week) based on international recommendations [22].

\subsection{Sedentary Behavior}

The data for sedentary behavior were acquired using the Sedentary Behavior Questionnaire for Older Adults. Ten different types of sedentary behavior, such as watching television, screen time, reading, and transport-related behavior, were all included in the questionnaire which showed adequate test-retest reliability for total sedentary behavior (Spearman's correlation coefficients $=0.74$ ) [23]. We dichotomized sedentary behavior measurements into two groups (high: $\geq 8 \mathrm{~h} /$ day, versus low: $<8 \mathrm{~h} /$ day) based on a previous study which reported that sitting for more than $8 \mathrm{~h} /$ day was related to increased all-cause mortality risks compared with those who did not [24].

\subsection{Covariates}

Self-reported sociodemographic variables, namely sex, age, educational achievement, occupational categorization, marital status, and accommodation situation, were collected and classified into categories. We categorized age into two groups (65-74 years, or 75 years and above). We also dichotomized educational achievement (high school degree and lower, or higher than high school degree), occupational categorization (with a full-time job, or without a full-time job, including unemployed, student, and retired), marital status (married, or not married, including single, divorced/separated, and widowed), and accommodation situation (solitary, or living together with others).

\subsection{Data Analyses}

Complete data for all the studied variables from 1068 older adults were analyzed. Chi-square analysis was used to examine differences between men and women. Then, adjusted logistic regression analyses were conducted to investigate the association of area-level crime incidence with the odds ratios (ORs) of engaging in sufficient physical activity (150+ min/week) and excessive sedentary behavior ( $\geq 8 \mathrm{~h} /$ day) after adjusting for the covariates. The multiple regression model assumes that linear association between the logit of the independent $\left(\mathrm{y}_{i}\right)$ and dependent variables $\left(P A_{i} / S B_{i}\right)$ with the associated covariates in the following form,

$$
\operatorname{logit}\left(\mathrm{y}_{i}\right)=\beta_{0}+\beta_{1} P A_{i} / S B_{i}+\beta_{2} \text { sex }_{i}+\beta_{3} \text { age }_{i}+\beta_{4} e d u_{i}+\beta_{5} \text { occup }_{i}+\beta_{6} \text { mar }_{i}+\beta_{7} \text { accom }_{i}
$$

In the above expression, the parameters $\beta$ represent the regression coefficient of every independent and covariate, the parameters sex $i$, age $_{i}$, edu $_{i}$, occup $_{i}$, mar $_{i}$, accom $i$ denote the categories of covariate variables (i.e., sex, age group, education, occupation, marital status, and accommodation) respectively. ORs and their $95 \%$ confidence intervals (CIs) for each studied variable were estimated. Statistical analyses were conducted using IBM SPSS 22.0. 


\section{Results}

Table 1 shows the sociodemographic variables of the sample of Taiwanese older adults. Among the participants, men accounted for approximately half (50.4\%), 64.4\% were aged 65-74 years, 69.9\% were educated to the level of lower than college, $89.8 \%$ with no full-time job, $75.7 \%$ were married, and $14.1 \%$ lived solitarily. In addition, approximately four fifths $(79.4 \%)$ of the participants had sufficient levels of physical activity and half of them (54.4\%) engaged in high levels of sedentary behavior. There was evidence for differences in educational achievement, occupational categorization, and marital status between men and women. Generally, women tended to have a higher proportion of lower educational achievement, without a full-time job, and were not married.

Table 1. Sociodemographic characteristics of participants $(n=1068)$.

\begin{tabular}{|c|c|c|c|c|c|c|c|}
\hline & \multicolumn{2}{|c|}{ Total } & \multicolumn{2}{|c|}{ Men } & \multicolumn{2}{|c|}{ Women } & \multirow{2}{*}{$p$-Value } \\
\hline & $\mathbf{N}$ & $\%$ & $\mathbf{N}$ & $\%$ & $\mathbf{N}$ & $\%$ & \\
\hline Age Groups & & & & & & & 0.176 \\
\hline $65-74$ years & 688 & $64.4 \%$ & 336 & $62.5 \%$ & 352 & $66.4 \%$ & \\
\hline 75 years or above & 380 & $35.6 \%$ & 202 & $37.5 \%$ & 178 & $33.6 \%$ & \\
\hline Educational achievement & & & & & & & $<0.001$ \\
\hline High school degree and lower & 747 & $69.9 \%$ & 347 & $64.5 \%$ & 400 & $75.5 \%$ & \\
\hline Higher than high school degree & 321 & $30.1 \%$ & 191 & $35.5 \%$ & 130 & $24.5 \%$ & \\
\hline Occupational categorization & & & & & & & 0.001 \\
\hline Without a full-time job & 959 & $89.8 \%$ & 467 & $86.8 \%$ & 492 & $92.8 \%$ & \\
\hline With a full-time job & 109 & $10.2 \%$ & 71 & $13.2 \%$ & 38 & $7.2 \%$ & \\
\hline Marital status & & & & & & & $<0.001$ \\
\hline Married & 809 & $75.7 \%$ & 438 & $81.4 \%$ & 371 & $70.0 \%$ & \\
\hline Not married & 259 & $24.3 \%$ & 100 & $18.6 \%$ & 159 & $30.0 \%$ & \\
\hline Accommodation situation & & & & & & & 0.991 \\
\hline Solitary & 151 & $14.1 \%$ & 76 & $14.1 \%$ & 75 & $14.2 \%$ & \\
\hline Living together with others & 917 & $85.9 \%$ & 462 & $85.9 \%$ & 455 & $85.8 \%$ & \\
\hline Physical activity & & & & & & & 0.631 \\
\hline Sufficient ( $\geq 150 \mathrm{~min} / \mathrm{wk})$ & 848 & $79.4 \%$ & 424 & $78.8 \%$ & 424 & $80.0 \%$ & \\
\hline Insufficient (<150 $\mathrm{min} / \mathrm{wk}$ ) & 220 & $20.6 \%$ & 114 & $21.2 \%$ & 106 & $20.0 \%$ & \\
\hline Sedentary behavior & & & & & & & 0.368 \\
\hline $\operatorname{High}(\geq 8 \mathrm{hr} / \mathrm{d})$ & 581 & $54.4 \%$ & 300 & $55.8 \%$ & 281 & $53.0 \%$ & \\
\hline Low $(<8 \mathrm{hr} / \mathrm{d})$ & 487 & $45.6 \%$ & 238 & $44.2 \%$ & 249 & $47.0 \%$ & \\
\hline
\end{tabular}

Generally, the results showed that crime incidence was negatively related to physical activity and positively associated with sedentary behavior among older adults. The results also showed that older adults living in the area with higher incidence of total crimes, drug crimes, theft, motor vehicle theft, and locomotive theft were less likely to achieve sufficient physical activity (more than $150 \mathrm{~min} /$ week). By contrast, the results also indicated that older adults living in the area with higher incidence of total crimes, drug crimes, breaking and entering, motor vehicle theft, locomotive theft, and rape were more likely to engage in excessive sedentary behavior (more than $8 \mathrm{~h} /$ day) (as Table 2).

Furthermore, there was a marked sex difference between the associations. In summary, the negative associations of different types of crime and physical activity were only observed in men; by contrast, the positive relationships of different types of crime and sedentary behavior were only observed in women (as Table 3). 
Table 2. Adjusted odds ratios (ORs) and 95\% confidence intervals (95\% CI) for the association of area-level crimes with physical activity and sedentary behavior in older adults.

\begin{tabular}{|c|c|c|c|c|c|c|}
\hline \multirow{2}{*}{ Type of Crime } & \multicolumn{3}{|c|}{ Achieving Sufficient Physical Activity } & \multicolumn{3}{|c|}{ Higher Sedentary Time } \\
\hline & OR & $(95 \% \mathrm{CI})$ & $p$-Value & OR & $(95 \% \mathrm{CI})$ & $p$-Value \\
\hline \multicolumn{7}{|l|}{ Total Crimes } \\
\hline Low (<194 events) & 1.00 & & & 1.00 & & \\
\hline High ( $\geq 194$ events) & 0.73 & $(0.53,0.99)$ & 0.04 & 1.70 & $(1.31,2.20)$ & $<0.001$ \\
\hline \multicolumn{7}{|l|}{ Drug crimes } \\
\hline Low (<143 events) & 1.00 & & & 1.00 & & \\
\hline High ( $\geq 143$ events) & 0.70 & $(0.51,0.95)$ & 0.02 & 1.64 & $(1.27,2.13)$ & $<0.001$ \\
\hline \multicolumn{7}{|l|}{ Theft } \\
\hline None & 1.00 & & & 1.00 & & \\
\hline At least 1 event & 0.72 & $(0.53,0.99)$ & 0.04 & 1.27 & $(0.98,1.64)$ & 0.07 \\
\hline \multicolumn{7}{|l|}{ Burglary } \\
\hline None & 1.00 & & & 1.00 & & \\
\hline At least 1 event & 0.96 & $(0.74,1.26)$ & 0.78 & 0.99 & $(0.79,1.24)$ & 0.95 \\
\hline \multicolumn{7}{|l|}{ Breaking and entering } \\
\hline Low ( $<7$ events) & 1.00 & & & 1.00 & & \\
\hline High ( $\geq 7$ events) & 0.83 & $(0.61,1.13)$ & 0.23 & 1.60 & $(1.23,2.07)$ & $<0.001$ \\
\hline \multicolumn{7}{|l|}{ Motor vehicle theft } \\
\hline Low ( $<7$ events) & 1.00 & & & 1.00 & & \\
\hline High ( $\geq 7$ events) & 0.70 & $(0.52,0.96)$ & 0.02 & 1.35 & $(1.05,1.74)$ & 0.02 \\
\hline \multicolumn{7}{|l|}{ Locomotive theft } \\
\hline Low (<16 events) & 1.00 & & & 1.00 & & \\
\hline High ( $\geq 16$ events) & 0.69 & $(0.51,0.94)$ & 0.02 & 1.37 & $(1.06,1.77)$ & 0.02 \\
\hline \multicolumn{7}{|l|}{ Rape } \\
\hline None & 1.00 & & & 1.00 & & \\
\hline At least 1 event & 0.90 & $(0.66,1.23)$ & 0.51 & 1.32 & $(1.02,1.72)$ & 0.04 \\
\hline
\end{tabular}

Analyses were adjusted for sex, age group, educational achievement, occupational categorization, marital status, and accommodation situation. 95\% confidence intervals of odds ratios that do not include one are highlighted in bold. 
Table 3. Adjusted odds ratios (ORs) and 95\% confidence intervals (95\% CI) for the association of area-level crimes with physical activity and sedentary behavior in older adults by sex.

\begin{tabular}{|c|c|c|c|c|c|c|c|c|c|c|c|c|}
\hline \multirow{3}{*}{ Type of Crime } & \multicolumn{6}{|c|}{ Men } & \multicolumn{6}{|c|}{ Women } \\
\hline & \multicolumn{3}{|c|}{ Achieving Sufficient Physical Activity } & \multicolumn{3}{|c|}{ Higher Sedentary Time } & \multicolumn{3}{|c|}{ Achieving Sufficient Physical Activity } & \multicolumn{3}{|c|}{ Higher Sedentary Time } \\
\hline & OR & $(95 \% \mathrm{CI})$ & $p$-Value & OR & $(95 \% \mathrm{CI})$ & $p$-Value & OR & $(95 \% \mathrm{CI})$ & $p$-Value & OR & $(95 \% \mathrm{CI})$ & $p$-Value \\
\hline \multicolumn{13}{|l|}{ Total crimes } \\
\hline Low (<194 events) & 1.00 & & & 1.00 & & & 1.00 & & & 1.00 & & \\
\hline High ( $\geq 194$ events) & 0.66 & $(0.43,1.02)$ & 0.06 & 1.44 & $(1.00,2.09)$ & 0.05 & 0.80 & $(0.51,1.25)$ & 0.33 & 1.96 & $(1.37,2.82)$ & $<0.001$ \\
\hline \multicolumn{13}{|l|}{ Drug crimes } \\
\hline Low (<143 events) & 1.00 & & & 1.00 & & & 1.00 & & & 1.00 & & \\
\hline High ( $\geq 143$ events) & 0.62 & $(0.40,0.96)$ & 0.03 & 1.41 & $(0.97,2.04)$ & 0.07 & 0.77 & $(0.50,1.21)$ & 0.26 & 1.87 & $(1.30,2.69)$ & $<0.001$ \\
\hline \multicolumn{13}{|l|}{ Theft } \\
\hline None & 1.00 & & & 1.00 & & & 1.00 & & & 1.00 & & \\
\hline At least 1 event & 0.61 & $(0.39,0.94)$ & 0.02 & 1.08 & $(0.75,1.55)$ & 0.70 & 0.91 & $(0.58,1.42)$ & 0.66 & 1.53 & $(1.06,2.20)$ & 0.02 \\
\hline \multicolumn{13}{|l|}{ Burglary } \\
\hline None & 1.00 & & & 1.00 & & & 1.00 & & & 1.00 & & \\
\hline At least 1 event & 1.00 & $(0.66,1.52)$ & 1.00 & 1.07 & $(0.75,1.52)$ & 0.71 & 0.94 & $(0.65,1.34)$ & 0.72 & 0.93 & $(0.70,1.24)$ & 0.63 \\
\hline \multicolumn{13}{|l|}{ Breaking and entering } \\
\hline Low ( $<7$ events) & 1.00 & & & 1.00 & & & 1.00 & & & 1.00 & & \\
\hline High ( $\geq 7$ events) & 0.82 & $(0.53,1.26)$ & 0.36 & 1.37 & $(0.94,1.97)$ & 0.10 & 0.84 & $(0.54,1.31)$ & 0.45 & 1.84 & $(1.28,2.65)$ & $<0.001$ \\
\hline \multicolumn{13}{|l|}{ Motor vehicle theft } \\
\hline Low ( $<7$ events) & 1.00 & & & 1.00 & & & 1.00 & & & 1.00 & & \\
\hline High ( $\geq 7$ events) & 0.71 & $(0.47,1.09)$ & 0.12 & 1.30 & $(0.91,1.87)$ & 0.15 & 0.71 & $(0.46,1.12)$ & 0.14 & 1.43 & $(1.00,2.05)$ & 0.05 \\
\hline \multicolumn{13}{|l|}{ Locomotive theft } \\
\hline Low (<16 events) & 1.00 & & & 1.00 & & & 1.00 & & & 1.00 & & \\
\hline High ( $\geq 16$ events) & 0.56 & $(0.37,0.87)$ & 0.01 & 1.10 & $(0.76,1.58)$ & 0.61 & 0.87 & $(0.56,1.35)$ & 0.53 & 1.71 & $(1.20,2.45)$ & $<0.001$ \\
\hline \multicolumn{13}{|l|}{ Rape } \\
\hline None & 1.00 & & & 1.00 & & & 1.00 & & & 1.00 & & \\
\hline At least 1 event & 0.78 & $(0.51,1.21)$ & 0.27 & 1.14 & $(0.79,1.64)$ & 0.50 & 1.06 & $(0.67,1.67)$ & 0.81 & 1.53 & $(1.04,2.23)$ & 0.03 \\
\hline
\end{tabular}

Analyses were adjusted for age group, educational achievement, occupational categorization, marital status, and accommodation situation. $95 \%$ confidence intervals of odds ratios that do not include one are highlighted in bold. 


\section{Discussion}

This study examined the relationship of area-level crime with older adults' physical activity and sedentary behavior in the Asian context. Consistent with previous studies reported on physical activity [13,14] and sedentary behavior [15], the main finding of the present study is that older Taiwanese adults living in an area with higher overall crime incidence were less likely to achieve the physical activity recommendations (150 $\mathrm{min} /$ week) and more likely to engage in excessive sedentary time ( $8 \mathrm{~h} /$ day). The results suggested that a lack of safety in the local area may discourage active lifestyles at the population level rather than for the individual victims. High area crime incidence may induce a lack of safely among people living in the neighboring area and taking actions for prevention. For example, worries about theft may contribute not only to reduce the time spent on outdoor physical activity but also to increase the time spent on indoor sedentary behavior. Consistent with a previous study for Norway [12], our findings showed violent crime (i.e., burglary, breaking and entering, and rape) was not associated with men's active behavior. The difference between these two studies based on different countries may be attributed to the criminal pattern. In Oslo, the capital of Norway, the amount of total crimes reported decreased but violent and weapons-related crimes increased in 2017 [25]. By contrast, in Taiwan, overall violent crime rates were among the lowest in the world [26]. Our results may have significant implications for informing local policy-makers and public health initiatives, where different types of crime prevention should be considered to be a strategy for promoting active and non-sedentary lifestyles among older adults.

Another novel result is that sex differences were observed in the relationship between crime incidence and active/sedentary behavior. Although numerous existing studies have found that the relationships between environment and physical activity vary by sex [27-29], only one study reported that violent crime incidence may have a larger impact on older men's physical activity than women's [12]. Our results confirmed and extended previous findings to show that area-level crime incidence might be more critical for older men's physical activity levels, and for older women's sedentary behavior. However, the possible mechanism for sex differences in the associations between crime safety and older adults' active/sedentary behavior remains unclear. A possible explanation could be that older men and women have different patterns of physical activity and sedentary behavior [30,31]. For example, older men may tend to engage in more moderate-to-vigorous physical activity and women tend to spend more time in sedentary behavior [32]. Therefore, it is possible that older men living in neighborhoods with higher crime incidence (i.e., presenting environmental barriers) may be less likely to engage in physical activity but that this may not affect their sedentary time to the same degree. In contrast, older women living in neighborhoods with higher crime incidence may have higher likelihood to have excessive sedentary time but that this would not impact upon their physical activity levels. Future studies using prospective designs to better understand these findings are still needed.

There are several limitations that need to be taken into consideration. The study is a cross-sectional design; thus, the observed associations between area-level crime and physical activity/sedentary behavior does not establish causality. The outcome measurements in this study were based on self-report, and therefore there may be a recall bias in our findings. Furthermore, the possible effect of self-selection was not considered to be a confounder in this study. For example, older adults who spend more time on physical activity may choose to live in neighborhoods with lower incidence of crime. Therefore, this would influence the associations between area-level crime and physical activity/sedentary behavior. This representativeness of the sample used in this study was limited because it was not possible to reach older adults without household telephones. However, according to official statistics, there were only $8.7 \%$ households that did not have a household telephone in 2017 [33].

\section{Conclusions}

These findings suggest that local crime prevention should be considered for policy-makers when designing physical activity and sedentary behavior interventions for older adults. In particular, area-level crime incidence appears to be more critical for older men's physical activity levels, and for older women's sedentary behavior. Future prospective studies are warranted to further examine these associations using both subjective and objective measures. 
Author Contributions: Conceptualization, C.-Y.L., M.-C.H., and Y.L.; Methodology, T.-F.L. and M.-C.H.; Software, C.-Y.L. and Y.L.; Investigation, T.-F.L., and Y.L.; Resources, M.-C.H.; J.-H.P.; Data Curation, C.-Y.L., and T.-F.L.; Writing-Original Draft Preparation, C.-Y.L., J.-H.P., M.-C.H., T.-F.L.; Writing-Review \& Editing, C.-Y.L., J.-H.P., M.-C.H., T.-F.L., and Y.L.; Supervision, J.-H.P., M.-C.H. and Y.L.; Funding Acquisition, J.-H.P. and Y.L.

Funding: Liao had a personal grant from the Ministry of Science and Technology of Taiwan (MOST 107-2410-H-003-117-MY2). This work was supported by a Global Research Network program through the Ministry of Education of the Republic of Korea and the National Research Foundation of Korea (NRF-Project number: NRF-2017S1A2A2038558).

Acknowledgments: This work is supported by "Higher Education Sprout Project" of the National Taiwan Normal University and the Ministry of Education, Taiwan, R.O.C.

Conflicts of Interest: The authors declare that they have no conflict of interest. The Ministry of Science and Technology of Taiwan was not involved in the study design, data collection, analysis, interpretation, and writing of the manuscript.

\section{References}

1. Inoue, S.; Sugiyama, T.; Takamiya, T.; Oka, K.; Owen, N.; Shimomitsu, T. Television viewing time is associated with overw eight/obesity among older adults, independent of meeting physical activity and health guidelines: Reply to Stabler and colleagues. J. Epidemiol. 2013, 23, 398. [CrossRef] [PubMed]

2. Bennie, J.A.; Pedisic, Z.; van Uffelen, J.G.; Gale, J.; Banting, L.K.; Vergeer, I.; Stamatakis, E.; Bauman, A.E.; Biddle, S.J. The descriptive epidemiology of total physical activity, muscle-strengthening exercises and sedentary behaviour among Australian adults-results from the National Nutrition and Physical Activity Survey. Bmc. Public Health 2016, 16, 73. [CrossRef] [PubMed]

3. Lin, C.Y.; Park, J.H.; Hsueh, M.C.; Sun, W.J.; Liao, Y. Prevalence of Total Physical Activity, Muscle-Strengthening Activities, and Excessive TV Viewing among Older Adults; and Their Association with Sociodemographic Factors. Int. J. Environ. Res. Public Health 2018, 15, 2499. [CrossRef] [PubMed]

4. Chang, S.H.; Hsueh, M.C.; Liao, Y. Personal and behavioral correlates of total and domain-specific sedentary behaviors in older Taiwanese adults. Bmc. Geriatr. 2018, 18, 294. [CrossRef] [PubMed]

5. Owen, N.; Sugiyama, T.; Eakin, E.E.; Gardiner, P.A.; Tremblay, M.S.; Sallis, J.F. Adults' sedentary behavior determinants and interventions. Am. J. Prev. Med. 2011, 41, 189-196. [CrossRef]

6. Sallis, J.F.; Cervero, R.B.; Ascher, W.; Henderson, K.A.; Kraft, M.K.; Kerr, J. An ecological approach to creating active living communities. Annu. Rev. Public Health 2006, 27, 297-322. [CrossRef]

7. Barnett, D.W.; Barnett, A.; Nathan, A.; Van Cauwenberg, J.; Cerin, E. Council on Environment and Physical Activity -Older Adults Working, G., Built environmental correlates of older adults' total physical activity and walking: A systematic review and meta-analysis. Int. J. Behav. Nutr. Phys. Act. 2017, 14, 103. [CrossRef] [PubMed]

8. Van Cauwenberg, J.; Nathan, A.; Barnett, A.; Barnett, D.W.; Cerin, E. Council on Environment and Physical Activity -Older Adults Working, G., Relationships Between Neighbourhood Physical Environmental Attributes and Older Adults' Leisure-Time Physical Activity: A Systematic Review and Meta-Analysis. Sports Med. (Auckl. N.Z.) 2018, 48, 1635-1660. [CrossRef] [PubMed]

9. Hsueh, M.C.; Liao, Y.; Chang, S.H. Perceived Neighborhood and Home Environmental Factors Associated with Television Viewing among Taiwanese Older Adults. Int. J. Environ. Res. Public Health 2016, 13, 708. [CrossRef]

10. Van Cauwenberg, J.; De Donder, L.; Clarys, P.; De Bourdeaudhuij, I.; Owen, N.; Dury, S.; De Witte, N.; Buffel, T.; Verte, D.; Deforche, B. Relationships of individual, social, and physical environmental factors with older adults' television viewing time. J. Aging Phys. Act. 2014, 22, 508-517. [CrossRef]

11. Oyeyemi, A.L.; Kolo, S.M.; Oyeyemi, A.Y.; Omotara, B.A. Neighborhood environmental factors are related to health-enhancing physical activity and walking among community dwelling older adults in Nigeria. Physiother. Theory Pract. 2018, 1-10. [CrossRef]

12. Piro, F.N.; Noss, O.; Claussen, B. Physical activity among elderly people in a city population: The influence of neighbourhood level violence and self perceived safety. J. Epidemiol. Community Health 2006, 60, 626-632. [CrossRef]

13. King, D. Neighborhood and individual factors in activity in older adults: Results from the neighborhood and senior health study. J. Aging Phys. Act. 2008, 16, 144-170. [CrossRef] 
14. Strath, S.J.; Greenwald, M.J.; Isaacs, R.; Hart, T.L.; Lenz, E.K.; Dondzila, C.J.; Swartz, A.M. Measured and perceived environmental characteristics are related to accelerometer defined physical activity in older adults. Int. J. Behav. Nutr. Phys. Act. 2012, 9, 40. [CrossRef]

15. Barnett, A.; Cerin, E.; Ching, C.S.; Johnston, J.M.; Lee, R.S. Neighbourhood environment, sitting time and motorised transport in older adults: A cross-sectional study in Hong Kong. BMJ. Open 2015, 5, e007557. [CrossRef]

16. Garcia Bengoechea, E.; Spence, J.C.; McGannon, K.R. Gender differences in perceived environmental correlates of physical activity. Int. J. Behav. Nutr. Phys. Act. 2005, 2, 12. [CrossRef]

17. Liao, Y.; Lin, C.Y.; Huang, J.H.; Park, J.H. Gender differences in the associations between perceived environment and walking for recreation in Taiwanese adults. Women Health 2017, 57, 551-565. [CrossRef]

18. National Police Agency, Ministry of the Interior. Crime Statistics. 2019. Available online: https://data. moi.gov.tw/MoiOD/Data/DataDetail.aspx?oid=6D9C7F00-3E4C-4FC7-BEDB-28D70FF96FEE (accessed on 24 February 2019).

19. Astell-Burt, T.; Feng, X.; Kolt, G.S. Identification of the impact of crime on physical activity depends upon neighbourhood scale: Multilevel evidence from 203,883 Australians. Health Place 2015, 31, 120-123. [CrossRef]

20. Macfarlane, D.J.; Lee, C.C.; Ho, E.Y.; Chan, K.L.; Chan, D.T. Reliability and validity of the Chinese version of IPAQ (short, last 7 days). J. Sci. Med. Sport 2007, 10, 45-51. [CrossRef]

21. Deng, H.B.; Macfarlane, D.J.; Thomas, G.N.; Lao, X.Q.; Jiang, C.Q.; Cheng, K.K.; Lam, T.H. Reliability and validity of the IPAQ-Chinese: The Guangzhou Biobank Cohort study. Med. Sci. Sports Exerc. 2008, 40, 303-307. [CrossRef]

22. Haskell, W.L.; Lee, I.M.; Pate, R.R.; Powell, K.E.; Blair, S.N.; Franklin, B.A.; Macera, C.A.; Heath, G.W.; Thompson, P.D.; Bauman, A. Physical activity and public health: Updated recommendation for adults from the American College of Sports Medicine and the American Heart Association. Circulation 2007, 116, 1081-1093. [CrossRef]

23. Ku, P.W.; Sun, W.J.; Chen, L.J. Development of the Sedentary Behavior Questionnaire for the Elderly. Sports Exerc. Res. 2016, 18, 41-55. [CrossRef]

24. Van der Ploeg, H.P.; Chey, T.; Korda, R.J.; Banks, E.; Bauman, A. Sitting time and all-cause mortality risk in 222497 Australian adults. Arch. Intern. Med. 2012, 172, 494-500. [CrossRef]

25. Norway 2019 Crime E Safety Report; Overseas Security Advisory Council: Washington, DC, USA, 2019.

26. Taiwan 2018 Crime \& Safety Report; Overseas Security Advisory Council: Washington, DC, USA, 2018.

27. Pelclova, J.; Fromel, K.; Cuberek, R. Gender-specific associations between perceived neighbourhood walkability and meeting walking recommendations when walking for transport and recreation for Czech inhabitants over 50 years of age. Int. J. Environ. Res. Public Health 2013, 11, 527-536. [CrossRef]

28. Gebel, K.; Slymen, D.; Frank, L.; Saelens, B.; Conway, T.; Cain, K.; Sallis, J. Neighborhood walkability, income and physical activity: Moderating effects of gender. J. Sci. Med. Sport 2012, 15, S219. [CrossRef]

29. Kelley, E.A.; Kandula, N.R.; Kanaya, A.M.; Yen, I.H. Neighborhood Walkability and Walking for Transport Among South Asians in the MASALA Study. J. Phys. Act. Health 2016, 13, 514-519. [CrossRef]

30. Bellettiere, J.; Carlson, J.A.; Rosenberg, D.; Singhania, A.; Natarajan, L.; Berardi, V.; LaCroix, A.Z.; Sears, D.D.; Moran, K.; Crist, K.; et al. Gender and Age Differences in Hourly and Daily Patterns of Sedentary Time in Older Adults Living in Retirement Communities. PLoS ONE 2015, 10, e0136161. [CrossRef]

31. Amagasa, S.; Fukushima, N.; Kikuchi, H.; Takamiya, T.; Oka, K.; Inoue, S. Light and sporadic physical activity overlooked by current guidelines makes older women more active than older men. Int. J. Behav. Nutr. Phys. Act. 2017, 14, 59. [CrossRef]

32. Ku, P.W.; Fox, K.R.; Chen, L.J. Physical activity and depressive symptoms in Taiwanese older adults: A seven-year follow-up study. Prev. Med. 2009, 48, 250-255. [CrossRef]

33. Directorate General of Budget, Accounting and Statistics, Taiwan. Report on the Survey of Family Income and Expendture. 2017. Available online: https://win.dgbas.gov.tw/fies/a11.asp?year=106 (accessed on 25 April 2019).

(C) 2019 by the authors. Licensee MDPI, Basel, Switzerland. This article is an open access article distributed under the terms and conditions of the Creative Commons Attribution (CC BY) license (http://creativecommons.org/licenses/by/4.0/). 